\title{
EDITORIAL
}

\section{TIME TO TAKE PREVENTION SERIOUSLY}

The International Review of the Red Cross seeks to address urgent humanitarian issues, with a view to offering solutions: beyond the necessary repressive or remedial measures, it is striking to note how many contributions in our pages actually point to the need to prevent certain patterns of violence and even put a halt to human suffering. These are not only calls for respect of human life and dignity; often, authors include practical suggestions on ways to achieve it. For instance, recent international efforts to address the issues of violence against health care ${ }^{1}$ and sexual violence in armed conflict ${ }^{2}$ have put forward a series of measures that States and non-State actors ${ }^{3}$ can put in place to translate the relevant legal provisions into practice, train relevant personnel on that basis, or educate the public at large.

There is a growing realization that it is necessary to put a special emphasis on efforts to prevent violations of international humanitarian law (IHL) and other applicable norms in armed conflict. How can we ensure that respect for human life and dignity remains a common concern shared by the opposing parties? More specifically, how does one generate respect for the law in times of war? What are the tools and strategies for influencing the behaviour of those participating in war, and of political decision-makers?

With this issue, the Review wants to take stock of the lessons learnt in the field of influencing behaviour and developing strategies for enhanced respect for the law and, more generally, to recall the importance of taking preventive measures to avoid the loss of the lives, livelihoods and prospects of entire generations.

\section{Respecting and ensuring respect for the law}

As a set of norms, IHL is the expression of an international consensus. It could be seen as a "social contract" between States to protect human life and dignity even in times when mortal peril could seem to justify all acts of violence.

It is in its faithful application by the parties to the conflict that the full power of IHL can unfold. States are the primary addressees of the obligation "to respect and ensure respect for IHL in all circumstances". ${ }^{4}$ Knut Dörmann and José Serralvo explain in their article that States are expected, first and foremost, to live up to their own obligations but also to abstain from assisting in the commission of violations by others, as well as to take measures to put an end to ongoing violations and to actively prevent their recurrence. 
At the level of the individual, the very existence of IHL and its continuous development could have been seen as a sufficient deterrence to IHL violations. After all, "ignorance is no excuse" (or "nul n'est censé ignorer la loi"): a person accused of having committed a crime cannot claim ignorance to avoid responsibility. Unfortunately, the existence of the law is not in itself a guarantee that it will be respected. Without proper implementation mechanisms, the law usually remains a rather weak tool for social order. Gustave Moynier, the first president of the International Committee of the Red Cross (ICRC) - and the founder of this journal - recognized this when he made the proposal to set up an international court back in $1872 .^{5}$

Indeed, the ad hoc tribunals for the former Yugoslavia and for Rwanda, the International Criminal Court, and other international courts and tribunals have been seen as "actors of deterrence" against the commission of war crimes and other serious violations of international law, with prosecutions serving to dissuade potential perpetrators from committing violations.

This issue of the Review devotes its Debate section and one article to the concrete effects that international and domestic criminal justice have had on fostering compliance with IHL. ${ }^{6}$ Though the discussion is not over, what can be said is that by virtue of their existence and jurisprudence, international courts and tribunals have significantly strengthened the international system of accountability for IHL violations.

Today, continuing efforts are put into the development of more effective compliance mechanisms in IHL. ${ }^{7}$ And yet, recent conflicts demonstrate an appalling disregard for elementary humanitarian considerations, and in some

1 See the thematic issues on "Violence against Health Care I/II", International Review of the Red Cross, Vol. 95, Nos 889, 890, 2013.

2 See the thematic issue on "Sexual Violence in Armed Conflict", International Review of the Red Cross, Vol. 95, No. 894, 2014.

3 On this point, in particular, and in relation to the provision of health care, see International Committee of the Red Cross (ICRC), "Safeguarding the Provision of Health Care: Operational Practices and Relevant International Humanitarian Law Concerning Armed Groups”, June 2015, available at: www.icrc.org/ eng/resources/documents/publication/p4243.htm (all internet references were accessed in September 2015).

4 Article 1 common to the four Geneva Conventions of 1949.

5 Gustave Moynier, "Note sur la création d'une institution judiciaire internationale propre à prévenir et à réprimer les infractions à la Convention de Genève", Bulletin International des Societes de Secours aux Militaires Blessés, No. 11, April 1872, p. 122. Writing in the aftermath of the Franco-Prussian war, Moynier struggled with many of the questions we still ask today regarding the effectiveness and normative value of the law in armed conflict. He was particularly concerned with the lack of effective mechanisms for implementing the rules of the 1864 Geneva Convention.

6 On the deterrent effect of international criminal justice, see the debate between Chris Jenks and Guido Acquaviva in this issue of the Review. On the role of domestic courts, see Sharon Weill's contribution in this issue. Also see the thematic issue of the Review on "Sanctions", Vol. 90, No. 870, 2008.

7 The Swiss government and the ICRC in particular have undertaken a major consultation process on how to improve compliance with IHL. For more information, see ICRC, "Strengthening Compliance with International Humanitarian Law (IHL): The Work of the ICRC and the Swiss Government", 21 April 2015, available at: www.icrc.org/eng/what-we-do/other-activities/development-ihl/strengthening-legalprotection-compliance.htm. 
instances even intentional violations of the law as a war tactic. In the face of such violations, how can one hope to influence the behaviour of parties to the conflict?

\section{If knowledge of the law can be a safeguard, sharing it is an obligation}

As early as 1869, Gustave Moynier wrote: "If the Convention is to be implemented, its spirit must be introduced into the customs of soldiers and of the population as a whole. Its principles must be popularized through extensive propaganda." Moynier's call seems to rest on two ideas: first, that the law must be known and understood, in order to be respected; and second, that there needs to be a proactive approach towards making the law known. Hence the quite unusual obligation for an international set of rules that IHL contains regarding its own dissemination. In legal terms, the importance of dissemination of IHL was first formally recognized in the 1906 Geneva Convention. ${ }^{8}$ The Geneva Conventions of 1949 contain a more elaborate obligation for States, ${ }^{9}$ which is reiterated and developed in the Additional Protocols. ${ }^{10}$ It was also found to be a customary rule of IHL. ${ }^{11}$

There are several dimensions to this obligation to disseminate IHL. First, it is primarily a responsibility of States, though Red Cross and Red Crescent actors also have a support role to play in promoting the law and assisting States in their efforts to do so. ${ }^{12}$ Second, unlike most other rules of IHL, it is also applicable in peacetime. Indeed, dissemination efforts are more likely to be successful when there is sufficient time and calm to expose different actors in society to IHL and humanitarian

8 Art. 26: "The signatory governments shall take the necessary steps ... to make [the provisions of this Convention] known to the people at large." The 1929 Geneva Convention also contains a similar obligation, in Article 27: "The High Contracting Parties shall take the necessary steps ... to bring [the provisions of this Convention] to the notice of the civil population."

9 See the obligation of States, in Articles 47/48 of the First and Second Geneva Conventions, to "undertake, in time of peace as in time of war, to disseminate the text of the present Convention as widely as possible in their respective countries, and, in particular, to include the study thereof in their programmes of military and, if possible, civil instruction, so that the principles thereof may become known to the entire population, in particular to the armed fighting forces, the medical personnel and the chaplains." Articles 127/144 of the Third and Fourth Geneva Conventions have similar wording, but specify that dissemination should be carried out among authorities responsible for the care of prisoners of war and civilian protected persons respectively. ${ }^{10}$ For a good overview of the obligation to disseminate the law, see Sandesh Sivakumaran, The Law of Non-international Armed Conflicts, Oxford University Press, Oxford, 2012, Chapter 10, section 2 on dissemination, pp. 434-437.

10 See Additional Protocol I (AP I), Art. 83; and Additional Protocol II (AP II), Art. 19. AP I asks for specific measures with a view to strengthening the general obligation (see Art. 6 on qualified persons, Art. 82 on legal advisers in armed forces, and Art. 87(2) on the duty of commanders). AP II extends the scope of application of the obligation to non-international armed conflicts.

11 See ICRC, "Customary IHL" database, Rule 142 (vis-à-vis the parties to the conflict) and Rule 143 (vis-àvis the civilian population), available at: www.icrc.org/customary-ihl/eng/.

12 The ICRC's mandate is given in Arts 5(2)(g) and 5(4)(a) of the Statutes of the International Red Cross and Red Crescent Movement (1986). The National Red Cross and Red Crescent Societies are mandated to disseminate IHL by Art 3 of the Statutes. Finally, the International Federation of Red Cross and Red Crescent Societies also has a role to play, as per Art 6(4)(j) of the Statutes. 
principles, so that real norm integration can take place. Third, non-State actors are also the addressees of these rules. ${ }^{13}$ Finally, the drafters of the text understood that military instruction was not sufficient and that the principles of IHL had to be known beyond the military, among the entire population.

But how does one effectively engage in the promotion, education and integration of IHL among the military and civilian population? While the 1949 Geneva Conventions specify the material, temporal and personal scope of the obligation to disseminate, they do not elaborate on the methods that have to be used to translate the legal obligation into actual respect and compliance by individuals.

\section{Understanding the roots of behaviour of combatants}

Military strategies and tactics have been studied since time immemorial in military treatises, ${ }^{14}$ mostly with a view to helping commanders and sovereigns win battles and wars. The systematic study of the factors that influence and shape the behaviour of individual combatants began much more recently. ${ }^{15}$ This was not necessarily rooted in the need to better regulate their conduct; rather it was intended to increase their efficacy in killing the enemy after the Second World War, the US Army realized that a majority of soldiers would actually not fire their weapons, even in the heat of battle, out of a "fear of aggression" and the deeply rooted prohibition against killing. ${ }^{16}$ The military training techniques that were subsequently developed apparently led to a significant increase in the firing rate of US soldiers in Korea and Vietnam, proving that individuals can be conditioned to adopt a more aggressive behaviour through "moral disengagement". ${ }^{17}$

The horrors of the Shoah and other crimes committed by the Nazi regime led to a deep interrogation on the possibility of turning any individual into an agent of a criminal undertaking, independent of any psychopathic predisposition. This

13 Regarding non-State armed groups, see common Art. 3 and AP II, Art. 19, which bind the "parties to the conflict". For a discussion on practical measures for encouraging armed groups to respect the law, see Michelle Mack, Increasing Respect for International Humanitarian Law in Non-International Armed Conflicts, ICRC, Geneva, 2008; and the thematic issues of the Review on "Understanding Armed Groups" (Vol. 93, No. 882, 2011) and "Engaging Armed Groups" (Vol. 93, No. 883, 2011).

14 The military treatise The Art of War, by Sun Tzu, dates back to the sixth century BC.

15 In France, Charles Ardant du Picq was a pioneer of the study of the psychology of combatants in the nineteenth century. In his work, Battle Studies, he stated: "Let us then study man in battle, for it is he who really fights." Ardant du Picq, Battle Studies: Ancient and Modern Battle, 1921, 8th ed., English translation available at: www.gutenberg.org/files/7294/7294-h/7294-h.htm.

16 Brigadier General Samuel Lyman Atwood Marshall, Men Against Fire: The Problem of Battle Command in Future War, Infantry Journal, Washington, DC, 1947.

17 For an analysis of the impact of military training on the firing rate of the US soldier, see Dave Grossman, On Killing: The Psychological Cost of Learning to Kill in War and Society, Black Bay Books, New York, 1996. More recently, Michel Goya's Sous le feu: La mort comme hypothèse de travail, Tallandier, Paris, 2014, analyzes the specific psychological conditions that combat in recent conflicts has created. On "moral disengagement", see Albert Bandura, "Selective Moral Disengagement in the Exercise of Moral Agency", Journal of Moral Education, Vol. 31, No. 2, 2002, pp. 101-119. 
disturbing idea is best captured in the subtitle that Hanna Arendt gave to her account of the Eichmann trial: A Report on the Banality of Evil. ${ }^{18}$

Regarding obedience to authority figures, the most famous study remains the seminal work of Stanley Milgram. ${ }^{19}$ It was based on a series of social psychology experiments measuring the willingness of study participants to obey an authority figure who instructed them to perform acts conflicting with their personal conscience by inflicting physical punishment on other people. Since then, several studies have been devoted to the reasons why IHL is violated in times of war based on psychological, economic, opportunistic or political arguments. ${ }^{20}$

In 2004, the ICRC published a study entitled "The Roots of Behaviour in War: Understanding and Preventing IHL Violations"; this study aimed to identify the factors which affect the behaviour of combatants in armed conflicts, with a view to better informing the ICRC's own prevention activities. ${ }^{21}$ According to the conclusions of the study, "disseminating" IHL (as the Geneva Conventions put it) has to be seen as a first step only, but one of crucial importance. Dissemination of information is rarely sufficient on its own, but should be seen as one aspect of a larger effort to build an environment conducive to respect for the law, which includes education, training, and integration of the law into instructions, orders and procedures. Just like in any military drill, which aims to create reflexive actions, military IHL training should aim to internalize norms through attitudinal change, discourse and repetition. ${ }^{22}$ The study also found that, besides the training of the weapons bearers, IHL also needs to be integrated into orders and instructions, in order to be respected. ${ }^{23}$ Consequently, the ICRC sought to integrate IHL into military doctrine and regulation, training, equipment and sanctions, rather than simply imparting knowledge on IHL. ${ }^{24}$ The study is currently being updated, as explained by Prof. Emmanuele Castano, chair of psychology at the New School for Social Research in New York, in his interview for the Review. This issue also provides ample space to experts sharing the most recent lessons learnt and reflections in the field of military training and integration of humanitarian law into military orders, with a view to reinforcing the effectiveness of prevention efforts.

18 Hannah Arendt, Eichmann in Jerusalem: A Report on the Banality of Evil, Penguin Books, New York, 1963.

19 Stanley Milgram, Obedience to Authority: An Experimental View, Harper \& Row, New York, 1974.

20 For instance, Eric David devotes a chapter of his book Principes de droit des conflits armés, Bruylant, Brussels, 1994, to this subject. On the behaviour of armed groups, see Olivier Bangerter, "Reasons Why Armed Groups Choose to Respect International Humanitarian Law or Not", International Review of the Red Cross, Vol. 93, No. 882, 2011, pp. 353-384.

21 See Daniel Muñoz-Rojas and Jean-Jacques Frésard, "The Roots of Behaviour in War: Understanding and Preventing IHL Violations", International Review of the Red Cross, Vol. 86, No. 853, 2004, pp. 189-206; Jean-Jacques Frésard, The Roots of Behaviour in War: A Survey of the Literature, ICRC, 2004, available at: www.icrc.org/eng/resources/documents/publication/p0854.htm.

22 See the contributions by Elizabeth Stubbins Bates and Raffaella Diana in this issue of the Review.

23 See the contributions by Andrew Carswell and Geoff Corn in this issue of the Review. Dale Stephens, also writing in this issue, challenges the assumptions made by the "Roots of Behaviour in War" study concerning the efficacy of the law; he argues that the role of identity and professional culture offers an effective means of ensuring restraint under the law.

24 See ICRC, Integrating the Law, Geneva, 2007, p. 17, available at: www.icrc.org/eng/assets/files/other/icrc002-0900.pdf. 


\section{Building an environment conducive to respect for the law}

The drafters of the Geneva Conventions realized that generating respect for the law goes beyond working with those who fight, that it requires a holistic approach. It ranges from the incorporation of IHL treaties into domestic $\operatorname{law}^{25}$ and the creation of a public discourse that is devoid of dehumanizing language aimed at any group, to ensuring appropriate knowledge, understanding and acceptance of the law by government officials, parliamentarians, academics, members of civil society, the media and so on.

Engaged in the promotion of IHL since its origins, ${ }^{26}$ the ICRC captured its lessons learnt and best practices in its Prevention Policy ${ }^{27}$ in 2007. The document synthesized the ICRC's actions as a constant effort to create "an environment conducive to respect for life and dignity (and for the ICRC's work)". This basic premise defines the organization's activities across different geographic regions and at different levels of dialogue with actors in society, while also aiming to ensure internal coherence of efforts.

Important prevention work can also be carried out with the highest government authorities bilaterally and in multilateral fora, as part of the diplomatic efforts by humanitarian organizations, at times supported by civil society campaigns.

Among all actors, the role of the media - and today social media - remains as important as ever. Even the most elusive groups are connected, and social media can be used to reach out to influential figures or networks which are sometimes impossible to access directly.

Still, nothing can replace direct face-to-face dialogue with the parties to the conflict and the civilian population, and this is closely linked to humanitarian operations. Growing insecurity due to crime and the radicalization of armed actors has created renewed interest in direct and personal interactions in the field in order to help gain access to conflict zones for humanitarian workers and pass IHL messages. The ICRC developed innovative approaches in the 1990s and 2000 s, and tried to engage systematically with a maximum of influential groups at the local level, notably through its field communication set-up. ${ }^{28}$

25 See the work of the ICRC's Advisory Services, for example, available at: www.icrc.org/en/war-and-law/ihldomestic-law. See also Cristina Pellandini's contribution in this issue of the Review.

26 In this issue of the Review, Marion Harroff-Tavel describes and analyzes the evolution of ICRC activities in the field of prevention since the organization's origins. She traces how the ICRC developed increasingly more sophisticated approaches and IHL tools to address the military, youth, academia and civil society, and makes insightful recommendations for future orientations of the approach.

27 ICRC, "International Committee of the Red Cross: Prevention Policy", International Review of the Red Cross, Vol. 91, No. 874, 2009, available at: www.icrc.org/eng/resources/documents/article/review/ review-874-p415.htm.

28 The ICRC's approach included SMS campaigns, campaigns to revive local customs on the conduct of hostilities, and systematic networking with local religious and tribal leaders, and so on. See, for instance, ICRC, "Somalia: Using Traditional Law in Disputes with Armed Groups", 11 November 2014, available at: www.icrc.org/en/document/somalia-using-traditional-law-dialogues-armed-groups. Recently, other organizations such as Geneva Call (in its engagement with armed groups) and Médecins Sans Frontières have also engaged in this type of work. See Geneva Call's mission statement at: www.genevacall.org/who-we-are/; and, for instance, Saleem Haddad, "Perception and Acceptance at Community Level: The Case of MSF in Yemen”, Humanitarian Exchange Magazine, No. 45, December 
Finally, one should not forget the important role that academia plays, not just in its purely educational dimension but also in terms of producing expertise, facilitating debate and conditioning future decision-makers. The Review asked several authors from academic institutions and new NGOs engaged in the promotion or teaching of IHL to share their experiences on this thematic issue. While their number has been growing over the years, they are still too few, and it is hoped that their accounts will inspire others.

\section{Looking ahead: Taking prevention seriously}

The objective of preventing IHL violations and encouraging respect for human dignity is an ambitious one. Following developments in research over the past decades, we now know much more about the various interrelated factors that could contribute to building an environment conducive to respect for the law. A wide range of pedagogical and academic tools have also been produced specifically tailored for the educational needs of the military, ${ }^{29}$ youth ${ }^{30}$ and higher education. ${ }^{31}$

Actors involved in the field of prevention can now move beyond the classic one-way dissemination approach and learn to embrace the complexity of factors influencing behaviour. This might require a series of measures.

First, a commitment to prevention needs political will, on the part of States and on the part of other actors involved in prevention. It requires the allocation of resources, the recruitment of competent staff, a concerted strategy and the capacity to coordinate with other actors so as to detect and reinforce complementarities. Investing in prevention means a commitment to continuity and long-term outcomes.

Second, there is a need for an increased emphasis on complementarity of efforts by actors involved in prevention. The goal of influencing behaviour clearly cannot be achieved by one actor alone. This means accepting that there is plenty of work to do for everyone, and looking at how to capitalize on complementarities, including with human rights organizations or actors involved

2009, available at: www.odihpn.org/humanitarian-exchange-magazine/issue-45/perception-andacceptance-at-community-level-the-case-of-msf-in-yemen.

29 Throughout the years, the ICRC has published a number of reference publications with the aim of assisting armed forces in incorporating the applicable law into military strategy, operations and tactics. See, for instance, ICRC, Handbook on International Rules Governing Military Operations, Geneva, 2013, available at: www.icrc.org/eng/resources/documents/publication/p0431.htm. The ICRC also organizes annual workshops for senior military officers to discuss the legal framework applicable to modern military operations and is regularly invited to provide the humanitarian perspective in training scenarios and military exercises of armed forces around the globe. For more information, see: www. icrc.org/en/armed-forces.

30 Exploring Humanitarian Law, for instance, is a resource pack for teachers aimed at introducing students aged 13-18 to the basic rules of IHL. It was designed by the ICRC in close association with the Education Development Center. The premise on which this project was built is that young members of society stand to benefit from discussions at an early age around respect for life and human dignity, civic responsibility, and solidarity. For more information, see: www.icrc.org/eng/what-we-do/building-respect-ihl/educationoutreach/ehl/exploring-humanitarian-law.htm.

31 For more information on the ICRC's work with academia, see: www.icrc.org/en/what-we-do/buildingrespect-ihl/education-outreach. 
in the development of the rule of law. Lack of coordination leads to duplication of efforts while leaving wide areas of needs unfulfilled.

Third, the rapid development of new technologies and global connectivity that the Internet provides are door-openers for actors working in this field to enhance their capacity to reach out to audiences worldwide. The crucial role of the Internet and the potential of digital education - while not remaining unexamined should be harnessed to reshape and further strengthen the prevention approach. In aiming for a more impactful outreach via new technologies, it should not be forgotten that prevention work is results-driven, rather than tools-driven.

Fourth, the field of prevention could benefit from better defining measurable objectives. In this regard, academic institutions, for instance, could help improve the accountability of prevention by regularly taking stock of ongoing prevention work and its evolution, or by developing platforms where instances of respect for the law and positive outcomes ("success stories") can be documented and shared.

Finally, it is important to acknowledge that prevention activities have a cost, especially in terms of maintaining qualified and well-trained staff, or the development of modern training and outreach tools. The costs are, however, symbolic compared to the money spent on remedial action during a conflict or on post-conflict rehabilitation activities. Interestingly, increasing donor emphasis on accountability over the last decade may have had the paradoxical effect of actors reducing the scope of more ambitious, long-term prevention programmes so as to deliver quick and highly visible results.

\section{People are people's own remedy}

"Hidden in this modest body of international law is an exhortation to knowledge, a call to study and understand, a demand that we take part in the rules", writes Naz Modirzadeh in her Opinion Note for this issue of the Review, calling for a renewed engagement with IHL. The norms of IHL embody the high aspirations of the international community. The idea that a common ground of humanity can be found in the midst of war - at a time when human life seems to have so little value-should be reaffirmed as one tying the members of the international community together. "People are people's own remedy" ("Nit nit ay garabam"), says a Senegalese proverb. It is time to act as our own remedy, reaffirm our trust in humanity and its future, and seriously commit to preventing abuses in armed conflict.

Over the past decades, actors working in the field of prevention have made considerable progress in understanding the roots of behaviour in war, and this knowledge should be put to good use. But more importantly, generating respect for the law is not simply a technical question - a matter of implementing a sound methodology in terms of influencing behaviour, military training or implementation of legal norms. It is also a matter of defending and regaining the moral high ground over those who want to turn crime into practice. 